\title{
IDÉIAS
}

equipes de "responsabilidades compartilhadas", dentro dn conceito Bradeford-Cohen (David L. Bradeford e Allan R. Cohen) em Excelência Empresarial onde "...em certos momentos inspiracionais mostram a qualidade da responsabilidade compartilhada; o lider não comanda, porém è seguido voluntariamente numa perseguição onde todos corram riscos. As apostas são altas, mas a crença na capacidade de vencer da equipe é geral. Porém, não existe uma imagem-chave para retratar lideres nessas situaçoes. Talvez a imagem se pareça com a de um treinador muito exigente, mas que oferece apoio e inspiração, que trabalha duro para manter a equipe unida, insiste em altos padrōes e esforços rigorosos, mas transmite todos os conhecimentos que irão ajudar os atletas a crescer. Este treinador freqüentemente trabalha ao lado da equipe, mas delega cada vez mais responsabilidades para o planejamento do jogo e, especialmente, para os ajustes do momento. Tudo isso inspira um grande esforço coletivo" (pág. 59).

Mais adiante conclui: "os gerentes-agentes aprendem a obter impacto sem exercer controle total. a ajudar sem ter todas as respostas, a se envolverem sem ficar no centro, a serem poderosos sem precisarem dominar, e a agirem de forma responsável sem pressionar em cxcesso"" (pág. 60).

Esses, os breves comentarios introdutórios à discussão sobrc o papel do DAS na administraçio publica, o papel do gerente da coisa pública, quer seja cla apresentada por simples papel a tramitar de um setor para outro, ou uma decisão de natureza estratćgica que vai mudar o curso da organizaçao que dirige.

As habilidades que o DAS deve desenvolver nos dias atuais para cumprir a sua missåo talvez possam ser mais bem repensadas e vivenciadas, a partir da reflexão do que foi anteriormente falado.

- Bradford, David L. \& Cohen, Allan R.

Excelência Empresarial

Editora Harper \& Row do Brasil Ltda - SP-1985.

- Toffler, Alvin

A Empresa Flexivel

Editora Record - Rio $\mathbf{9} 986$.

Texto elaborado para o treinamento de DAS do Governo do Estado do Piaui.

\section{Legalidade e Legitimidade da Despesa Pública}

Oswaldo Alves de Mattos (")

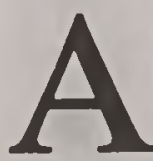
despesa publica tem seu processamento disciplinado em leis, decretos e normas complementares, pontificando a Lei № 4.320, de 17 de marco de 1964, que estatui normas gerais de Direito Financeiro para claboraça e controle dos orçamentos e balanços da União, dos Estados, dos Municipios e do Distrito Federal, como alicerce. Apesar de decorridos mais de 21 anos de vigência, sua sistcmática ainda resiste às incursoles dos tratadistas da área que lhc tîm feito algumas objeçoes.

E verdade que a Lei No 4.320/64 precisal de reformulação, entretan(1), nio ha como se lhe negar a valiosil contribuiçio que vem dando ao processo de controle das contas públicas.

()) recursos pủblicos não podem ser aplicados com despotismo. Nảo bastil a vontade do administrador para legitimar a despesa, ainda que cli esteja enquadrada em planos de governo anunciados como plataforma cleitoral.

A Constituição da República Federativa do Brasil, em seu artigo 60 , determina:

"Art. 60 - A despesa pública obedecerá à lei orçamentária anual, que nao conterá dispositivo estranho à fixação da despesa e à previsão da receita..."

Vê-se, assim, que a Carta Magna coloca o Orçamento anual como fator principal de limitação à ação do gestor. Perguntar-se-ia por que a Constituição não limitou à "receita pública"'e sim à "despesa pública"?

Pelo simples fato de que a despesa pública assume indices maiores

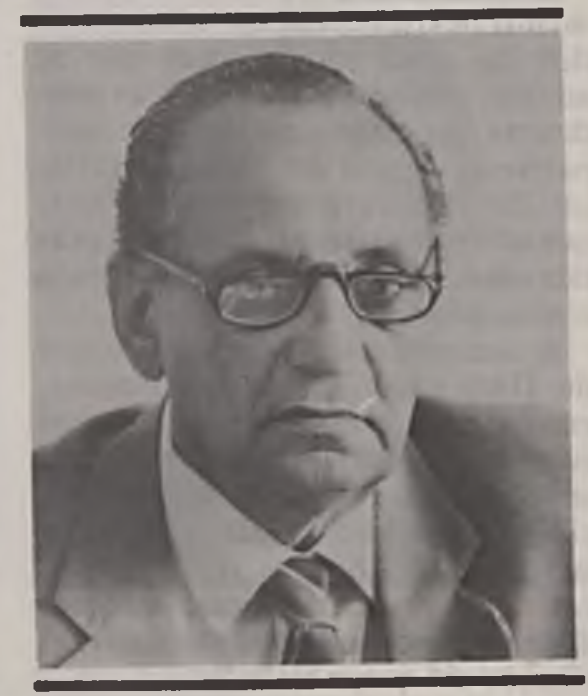

de preocupação do povo no complexo gestorial.

Não quer, com isso, dizer que a receita não tem importância. Até pelo contrário! O campo da receita pública tem sido relegado a segundo plano, numa omissão imperdoâvel do legislador.

Para um resultado financeiro positivo, tanto é importante o fator maior arrecadação, como o de menor despesa.

Uma administração voltada para - aperfeiçoamento dos métodos de arrecadação da receita colhe tantos ou melhores resultados quanto aquela preocupada em diminuir a despesa pública.

Poderiamos, até, afirmar que a gestão voltada para a eficiência da receita colhe melhores resultados. Uma administração deficiente da receita pública obrigará a cortes no orçamento da despesa, o que resultará em inexecução orçamentária, 
em termos de programas de Governo.

Afirmamos, com convicção, que no dia em que os Sistemas de Controle Interno e Externo atuarem na área da receita pública, com a mes ma intensidade que atuam no campo da despesa pública, os resultados serão bem mais expressivos, visto que: o nascimento e a extinção do crédito público sofreriam auditoria; as isençoes e imunidades seriam revistas; as remissões e os cancelamentos de divida ativa seriam examinados; os julgamentos das Cortes Fiscais teriam acompanhamento.

Não se diga que acabariam os favorecimentos, mas, logicamente, eles não ocorreriam com tanta facilidade, como hoje. Além disso, as omissões, no lançamento do crédito fiscal e na fiscalização, diminuiram. substancialmente.

Mas, voltando ao tema deste trabalho, diziamos que a despesa pública tem seu comportamento regulado em leis, decretos e outras normas complementares, como Portarias, Circulares, Resoluçōes etc.; com isso, muito se preocupam os que têm a responsabilidade de normatizar os dispêndios públicos.

Poucos, no entanto, preocupamsc, primeiramente, em conceituar o que é despesa pública, para fins de legitimidade e legalidade de sua realização.

O Orcamento Público resulta de lei, mas é um documento expresso em códigos, que traduzem o vulto da despesa por clemento. Educação, Saúde, Segurança, Transporte e outros são os campos gerais de atuação do Poder Público.

A despesa tem que possuir suportc orçamentário, mas sua realização deve subordinar-se, lambém, à arrecadação da receila, para não desequilibrar a execução orçamentária. Imaginamos uma balança onde, num prato, está a receita e, no ouI ro, a despesa. No inicio, a posição é de equilibrio e esse equilibrio deve permanecer até ofim do exercicio. Vê-se, pois, a preponderância que assume a realização da receita, sem o que não há execução da despesa.

Já, aí, vamos verificando que nào basta a existência de crédito orçamentário. $\dot{E}$ preciso que a dotação esteja libcrada, para fins de empenho, c a liberaça é feita em face do comportamento da receita. Mas é só isso? Nảo. Continuamos a pergun- tar o que é despesa pública? Educaçào, Saúde são despesas públicas ? Existem as escolas particulares, como existem os hospitais particulares. Transporte é serviço público? Mas pode ser concedido.

Cremos que a despesa será pública, não pela sua simples espécie, mas será pública, quando atender a uma necessidade pública qualquer e for realizada pelo Órgão Público competente e no interesse da comunidade local.

Tudo gira em torno do universo das necessidades públicas. As necessidades são ilimitadas e concorrentes. A cada minuto, criam-se novas necessidades. A evolução da sociedade impõe novas necessidades. Elas concorrem entre si, forçando a

No dia em que os
critérios de legalidade
c legitimidade da
despesa pública forem
obedecidos, chegarão ao
fim os excessos com
coquetéis, festinhas
internas, emprego de
veiculos para locomoções
particulares e outras
manifestações do
descaso com os recursos
públicos postos a
disposição do governo.

adoção de critérios de prioridade.

A necessidade pública existe ou surge de repente. A época de seu atendimento depende do interesse da comunidade.

Para atender a essas necessidades, estimula-se a criação de bens e servicos.

Havendo previsão de recursos orcamentários, a despesa, em principio, é cabivel, mas só adquire foro de legitimidade, pelo atendimento de uma necessidade pública, no interesse da comunidade e pelo Orgão competente, e aspecto de legalidade, quando seu processamento revestir-se das formalidades estabclecidas em lei ou regulamento.

O dia em que essas circunstâncias forem obedecidas, rigidamente, pelos administradores, teremos eliminadas da administração pública as despesas com coquetéis de confra- ternização, festas internas, locomocão para fins particulares e outras que, no fundo, de necessidade pública nada as legitima.

$\mathrm{Na}$ verdade, por trás dos números frios que expressam as dolaçōes orcamentárias, desenvolvem-se projetos completamente alheios à vontade popular.

As despesas, como dissemos, são concorrentes,e isto se dá porque a limilação de recursos financeiros impõe. Se houvesse dinheiro para atender a todas as despesas, num dado momento, não haveria necessidade de estabelecer critérios de prioridade.

E preciso, no entanto, que as prioridades sejarn fixadas não no sentido politico, mas, เāo-somente, no social.

Vale lembrar que, nos estados c municípios, é comum o enderecamento de recursos para obras públicas que valorizam a propriedade de alguns, tais como pontes, estradas. luz, água etc., em determinadas áreas, quando outras, de beneficio geral da comunidade, não são atendidas (por falta de recursos!).

Nesses casos, não se poderia lachar a despesa de ilegal ou ilegitima, mas de inoportuna.

$\mathrm{O}$ administrador vê-se, às vezes, diante de problemas sérios e fica em dúvida, quanto à legitimidade e legalidade ou não da despesa.

Um exemplo: lamentavelmente. tornou-se rotina, em época de eleicões, o Governo sofrer criticas, as mais variadas, que atingem a pessoa do administrador, mas, na maioria das vezes, atingem muito mais aos interesses da comunidade.

O Prefeito ou o Governador, se têm recursos financeiros particulares, defende-se, mas aquele que não os possui, fica à mercê de um julgamento onde não hà a defesa pelos mesmos veiculos da acusação.

Pergunta-se: è de justiça isso? Claro que não.

Ataques como esses, que declaram:

— falta de segurança;

- desconforto:

- roubo;

- hospedagem precária;

- transporte deficiente

atingem diretamente aos interesses económicos do estado ou do municipio, porque o turismo se retrai e os industriais nacionais e estrangeiros deixam de investir na localidade. 
Tal situação afeta as rendas públicas e provoca desemprego.

Pergunta-se, agora. Ė ou não legítima e legal a despesa feita, moderadamente, pelo administrador que rebate tais acusações? É ou não pública essa despesa?

Claro que sim. O que há de se exigir é moderação na resposta (defesa) e apelar para os desinformados acusadores, para que tenham consciência do que estão fazendo.

Assim, inúmeras despesas podem surgir que, expressamente, não estão previstas e, por isso mesmo, levam os analistas a admitir que seu atendimento carece de amparo legal. O que não é o caso. Ela se legitima, na medida em que atende a uma necessidade pública da comunidade.

Outro exemplo. Na esfera federal, podemos salientar as despesas realizadas na execução de projetos de assistência aos estados e municipios.

Ninguém desconhece os sérios problemas que enfrentam os prefeitos para cobrar seus créditos fiscais.

Sabe-se que a maioria dos municípios não cobra o Imposto Sobre Serviços - ISS e não adota critérios de reajustamento de valores para o IPTU.

Os prefeitos são coagidos pelos comerciantes, pelos profissionais liberais, pelos grandes proprietários, por todos aqueles que seriam atingidos pelas normas de imposiçito tributária.

Por isso mesmo, acomodam-se em viver dos repasses da Uniato c dos Estados. E mais confortável, menos trabalhoso.

Outras prefeituras nito cobram seus creditos por falta de estrutura, de organizaço, de recursos humanos e de conhecimentos de como proceder.

Agora mesmo, uma minireforma tributária vai alocar mais recursos para os municipios, mas também lhes irá transferir a responsabilidade do atendimento de vários serviços públicos.

Como proceder diante de tudo isso, sem uma assistência técnica?

Quanto menos arrecadarem recursos próprios, quanto menos administrarem sua divida ativa, quan10 mais deficiente for o atendimento das necessidades públicas municipais, mais precisarão os prefeitos de recursos da União.

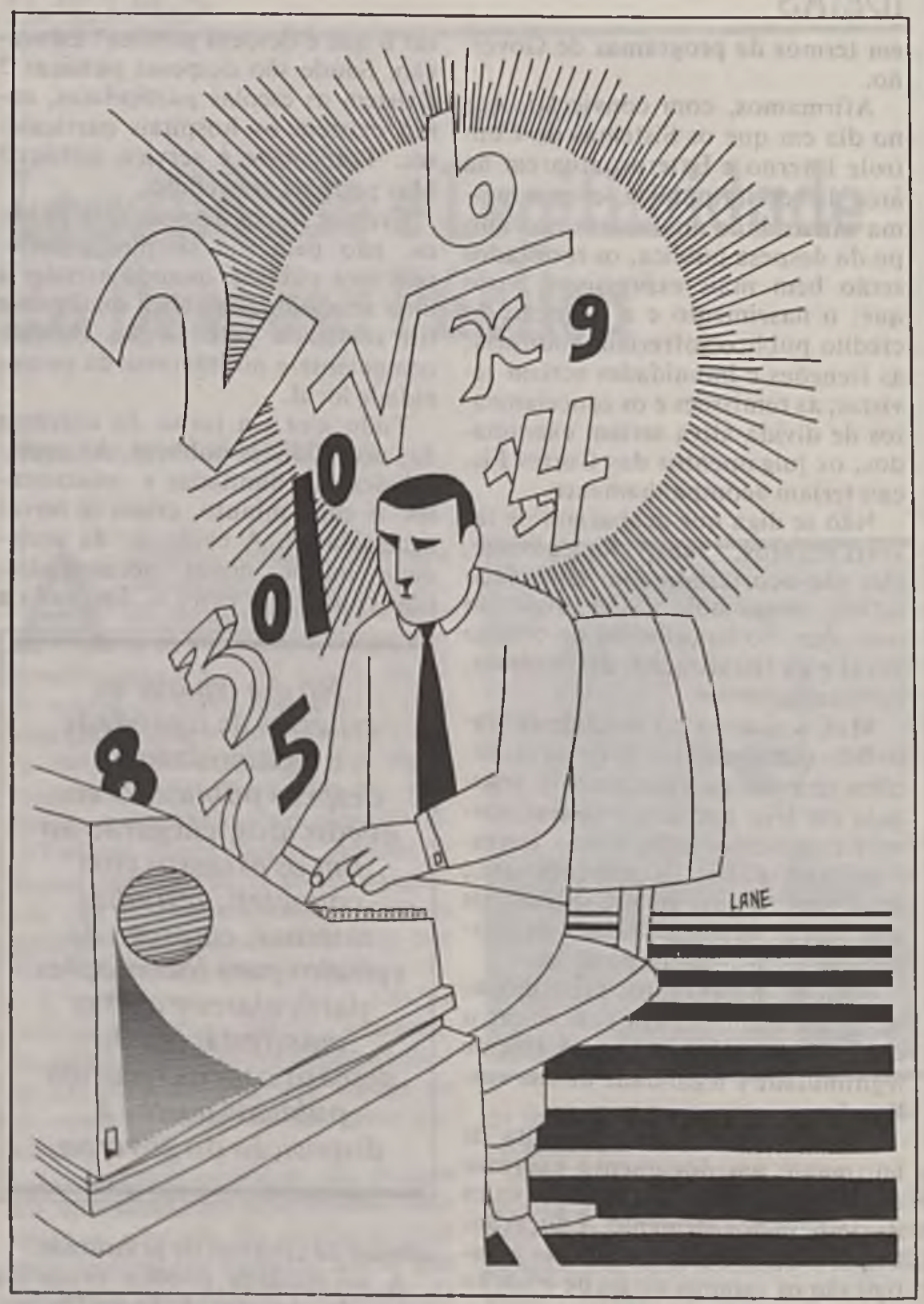

Na verdade, por trás dos números frios que expressam as dotações orçamentárias, fazem-se projetos completamente alheios a vontade popular.

Por isso, é preciso que as prioridades sejam

fixadas, não no sentido politico, mas tão-somente com objetivos sociais, corrigindo-se os desvios de destinação das verbas orçamentadas.
O interesse da União no aperfejcoamento da gestão municinal ć, nois, indiscutivel; dai, concluirmos que toda despesa com assistência técnica aos municipios, voltada para o aperfeiçoamento de suas estruturas organizacionais, c legitima, i legal e $\dot{c}$, até mesmo, recomendável como prioritária.

A administração publica há que ser encarada como um lodo c a estadual c a municipal como formas descentralizadas de gestajo.

Entendemos que a despesa publica deve revestir-se de dois aspectos fundamentais:

1 - o da legalidade e,

2 - o da legitimidade. 
A aquisição de determinado material pode estar conforme a legislação que a disciplina:

- recurso orçamentário;

- modalidade de licitação adequada: prido;

- prazo de fornecimento cum-

- pagamento na data certa.

Suponhamos, entretanto, que esse material adquirido, com todo aquele "colorido," seja:

- um condicionador de ar que ficou no almoxarifado 2 anos; ou

- um tapete persa, que foi colocado no gabinete da Secretária do Diretor.

Veja-se que, quanto à legalidade, não há restrições. As normas legais foram obedecidas. Havia verba, houve licitação etc., mas tais despesas atendiam a alguma necessidade, no momento de sua realização? Claro que não. No primeiro caso, deuse o que chamamos, vulgarmente, de aproveitamento do recurso orçamentário para não cancelar saldos. No segundo caso, foi mero exibicionismo pessoal do gestor.

Nenhuma dessas duas despesas tinha foros de legitimidade. $\mathrm{O}$ ato do ordenador não foi legítimo como ação, no sentido de despesa pública propriamente dita.

Se a necessidade pública não comanda a ação, a despesa torna-se desnecessária, a exemplo das estocagens absurdas de material, abarrotando os almoxarifados e fazendo crer que a aquisição contenha outras intençōes ou benefícios pessoais.

E nem se venha argumentar com uma série de despesas que existem, tais como cafezinhos, higiene pessoal, as próprias despesas de representação. É preciso que se entenda que a sociedade é organizada em no. me do povo. Ele, povo, precisa de seus organismos e de suas instituiç̃es, mas as despesas de manuten. ção e funcionamento hão que se limitar às estritas necessidades, com moderação e sem extravagâncias.

Concluimos, pois, que:

a) a legalidade da despesa pública adquire-se com a previsão orçamentária e o cumprimento das formalidades legais estabelecidas para sua realização;

b) a legitimidade caracteriza-se quando atender a uma necessidade pública da comunidade e o seu interesse determinar, além de ser realizada pela autoridade competente.

\section{A questão do docente no ensino superior federal}

\author{
(*) Paulo Vieira da Silva
}

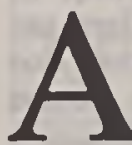

pesar de quase meio século de tentativas objetivas no sentido de conceitualizar e definir rumos para a institucionalização de uma política de mérito no serviço público, o fato é que até o presente momento muitas questōes ainda estão por ser resolvidas. Tal ocorre por um sem-número de razões que encontram raizes na própria estrutura de nossa sociedade.

Entre os pontos que precisam de esforço especial dos estudiosos, ressaltam aqueles que se referem ao mero conceito de carreira no serviço público. A bibliografia especializada em administração de pessoal ou de recursos humanos, trata de maneira aligeirada esse assunto. Por outro lado, a legislação que se refere ao ordenamento juridico dos servidores públicos não se tem comprometido em encontrar uma definição apresentável do que seja uma carreira. E a leitura atenta tanto de uma coisa como a de outra deixa uma forte impressão de que, em termos conceituais, tem predominado uma visåo faiolista que se esgota no mero esforço de definir o que é cargo público e quais as classes ou séries de classes em que eles se situam. Avançando um pouco além, procura-se explicar que a divisão de tarefas para cada um deles tem como referencial os niveis de complexidade e de responsabilidade previamente especificados.

Parece que o momento sugestivo para o aprofundamento desse assunto é o que se vive em termos de tentativas de elaboração de um novo

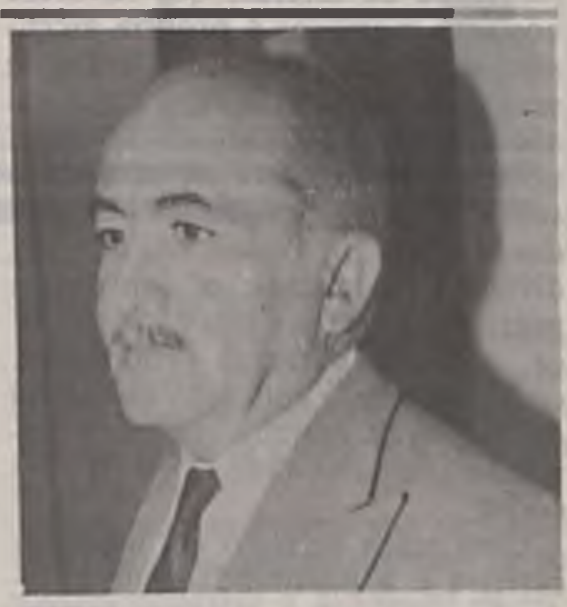

estatuto para os servidores públicos civis da União, e o da definição de mecanismos operacionais para o novo plano de cargos e salários para o pessoal docente de nivel superior das instituições federais, autárquicas ou fundacionais.

O propósito deste trabalho é o de trazer à discussão a questão da carreira, naquilo que ela tem de conceitualmente especifico, quando considerada nas entidades de ensino superior que agora contam com o referencial de um plano de cargos e salários, apresentando, ao final, algumas sugestōes à consideração dos setores interessados. O pressuposto é o de que a discussão do tema, para atender aos interesses do magistério superior, poderá também contribuir para o melhor entendimento do sentido de carreira no âmbito de interesse do funcionalismo público em geral.

(") Professor do Departamento de Administração da UnB e assessor legislativo da Cámara dos Deputados; mestre em Administraçăo Pública e Doutor (PhD) em Educação Superior pela Universidade do Sul da Califórnia 